\title{
Identification of Novel Bioactive Compound Derived from Rheum officinalis against Campylobacter jejuni NCTC11168
}

\author{
Mohammed Yosri ${ }^{D},{ }^{1}$ Basma H. Amin, ${ }^{1}$ Nermine N. Abed, ${ }^{2}$ Amal S. Elithy, ${ }^{2}$ \\ Sayed M. Kareem, ${ }^{1}$ and Nagwa M. Sidkey $\mathbb{D}^{2}$ \\ ${ }^{1}$ The Regional Center for Mycology and Biotechnology, Al-Azhar University, Nasr City, Cairo 11787, Egypt \\ ${ }^{2}$ Faculty of Science (Girls Branch), Al-Azhar University, Nasr City, Cairo, Egypt \\ Correspondence should be addressed to Mohammed Yosri; mohammed.yosri@yahoo.com
}

Received 20 January 2020; Revised 16 May 2020; Accepted 28 May 2020; Published 1 July 2020

Academic Editor: Antonio M. Rabasco

Copyright (c) 2020 Mohammed Yosri et al. This is an open access article distributed under the Creative Commons Attribution License, which permits unrestricted use, distribution, and reproduction in any medium, provided the original work is properly cited.

\begin{abstract}
Gastric diseases are increasing with the infection of Campylobacter jejuni. Late stages of infection lead to peptic ulcer and gastric carcinoma. C. jejuni infects people within different stages of their life, especially childhood, causing severe diarrhea; it infects around two-thirds of the world population. Due to bacterial resistance against standard antibiotic, a new strategy is needed to impede Campylobacter infections. Plants provide highly varied structures with antimicrobial use which are unlikely to be synthesized in laboratories. A special feature of higher plants is their ability to produce a great number of organic chemicals of high structural diversity, the so-called secondary metabolites. Twenty plants were screened to detect their antibacterial activities. Screening results showed that Rheum officinalis was the most efficient against C. jejuni. Fractionation pattern was obtained by column chromatography, while the purity test was done by thin-layer chromatography (TLC). The chemical composition of bioactive compound was characterized using GC-MS, nuclear magnetic resonance, and infrared analysis. Minimal inhibitory concentration (MIC) of the purified compound was $31.25 \mu \mathrm{g} / \mathrm{ml}$. Cytotoxicity assay on Vero cells was evaluated to be $497 \mu \mathrm{g} / \mathrm{ml}$. Furthermore, the purified bioactive compound activated human lymphocytes in vitro. The data presented here show that Rheum officinalis could potentially be used in modern applications aimed at the treatment or prevention of foodborne diseases.
\end{abstract}

\section{Introduction}

People at several stages of their life are infected by gastrointestinal bacteria including Campylobacter jejuni and Helicobacter pylori $[1,2]$. C. jejuni is a principle factor for diarrhea in developed countries $[3,4]$.

C. jejuni primarily infects large intestine and the distal portion of the small intestine so that it is able to cause changes in the environment around it by reducing the acidity; it interacts with host mucosa by surface adhesion proteins triggering proinflammatory responses, causing intestinal metaplasia, and develops at late stages to gastric adenocarcinoma $[5,6]$. It transmits to human by consuming either contaminated milk or raw meat $[7,8]$.

Due to bacterial resistance to antibiotics, a new alternative compound that possesses antibacterial activity should be found [9]. Medicinal plants have a large bank of rich and complex compounds which are unlikely to be synthesized in laboratories. Natural products from medicinal plants induce new agents or antimicrobial use. A special characteristic of these plants lies in their ability to produce a large number of organic chemicals of high structural diversity, which are called secondary metabolites. This study is aiming to find an alternative strategy to limit Campylobacter jejuni contamination and to impede Campylobacter jejuni infections using natural products $[10,11]$.

\section{Materials and Methods}

2.1. Bacteria and Media. C. jejuni NCTC 11168 was kindly obtained from the Department of Reproductive Diseases, Animal Reproduction Research Institute (ARRI), Giza, 
TABLE 1: Screening of the anti-Campylobacter jejuni activity of different plant extracts.

\begin{tabular}{lccc}
\hline Collected plants & Inhibited zone $\mathrm{H}_{2} \mathrm{O}$ extract & Inhibited zone methanol extract & Inhibited zone hexane extract \\
\hline Salvia officinalis & $8.03 \pm 0.25$ & $15.1 \pm 0.00$ & $12.0 \pm 0.00$ \\
Rosmarinus officinalis & $26.8 \pm 0.51$ & $18.0 \pm 0.00$ & $14.7 \pm 0.00$ \\
Foeniculum vulgare & $11.2 \pm 0.00$ & $20.1 \pm 0.00$ & $11.5 \pm 0.00$ \\
Hordeum vulgare & $10.3 \pm 0.00$ & $15.1 \pm 0.00$ & $20.6 \pm 0.00$ \\
Artemisia & $31.7 \pm 0.00$ & $20.4 \pm 0.00$ & $18.6 \pm 0.00$ \\
Anethum graveolens & $12.5 \pm 0.00$ & $15.2 \pm 0.00$ & $12.2 \pm 0.00$ \\
Costus & $7.7 \pm 0.00$ & $15.2 \pm 0.00$ & $17.3 \pm 0.00$ \\
Nigella sativa & $8.5 \pm 0.00$ & $10.6 \pm 0.00$ & $15.3 \pm 0.00$ \\
Commiphora myrrha & $16.4 \pm 0.00$ & $19.7 \pm 0.00$ & $30.2 \pm 0.00$ \\
Thymus vulgaris & $9.5 \pm 0.00$ & $9.3 \pm 0.32$ & $9.2 \pm 0.00$ \\
Matricaria chamomilla & $8.4 \pm 0.00$ & $15.1 \pm 0.00$ & $8.0 \pm 0.00$ \\
Achillea & $23.2 \pm 0.00$ & $8.2 \pm 0.30$ & $8.4 \pm 0.00$ \\
Plantago uniflora & $10.2 \pm 0.32$ & $10.5 \pm 0.00$ & $11.4 \pm 0.20$ \\
Cassia angustifolia & $28.2 \pm 0.30$ & $15.7 \pm 0.00$ & $23.1 \pm 0.20$ \\
Rheum officinalis & $24.1 \pm 0.00$ & $39.1 \pm 0.00$ & $20.2 \pm 0.00$ \\
Cinnamomum zeylanicum & $10.5 \pm 0.00$ & $15.4 \pm 0.00$ & $15.4 \pm 0.00$ \\
Allium sativum & $10.4 \pm 0.00$ & $10.1 \pm 0.00$ & $13.2 \pm 0.00$ \\
Lepidium sativum & $20.0 \pm 0.2$ & $9.9 \pm 0.00$ & $9.5 \pm 0.35$ \\
Trigonella foenum-graecum & $16.8 \pm 0.00$ & $19.2 \pm 0.1$ & $30.4 \pm 0.00$ \\
Senegalia senegal & $17.5 \pm 0.15$ & $22.4 \pm 0.00$ & $23.4 \pm 0.00$ \\
\hline
\end{tabular}

Egypt. Prior to test, this strain was cultured on brain heart infusion agar supplemented with $10 \%(\mathrm{v} / \mathrm{v})$ sterile defibrinated sheep blood and incubated at $42^{\circ} \mathrm{C}$ for $24 \mathrm{~h}$ in microaerobic conditions $\left(5 \% \mathrm{O}_{2}, 10 \% \mathrm{CO}_{2}\right.$, and $\left.85 \% \mathrm{~N}_{2}\right)$ in $\mathrm{CO}_{2}$ Incubator, Fisher, Germany.

2.2. Plant Collection and Extraction. Twenty plant roots were collected from traditional medicine shops as shown in $\mathrm{Ta}-$ ble 1. All plants were rinsed, sliced, dried $\left(50^{\circ} \mathrm{C}\right.$ for $\left.24 \mathrm{~h}\right)$, ground, and sieved ( 80 mesh); the fine particles were stored in a clean container for further analysis. Pure methanol, hexane, and sterile distilled water were used as solvents for extraction. Each solvent $(500 \mathrm{ml})$ was added to $50 \mathrm{~g}$ of each powdery plant material and homogenized for $20 \mathrm{~min}$ using homogenizer and then allowed to stand for 1 hour. Extracts were passed through a Whatman filter paper No. 1. Mixtures were then centrifuged at $6000 \mathrm{rpm}$ for $10 \mathrm{~min}$ to obtain clear extracts. Solvents were allowed to evaporate completely using a rotary evaporator, Fisher, USA. Then, the final extracts of each plant were completed up to $5 \mathrm{ml}$ of each solvent [12-14].

2.3. Antibacterial Assay. In brief, about $20 \mathrm{ml}$ of the medium was poured into sterile plates $(9 \mathrm{~cm})$ and allowed to solidify, and $5 \mathrm{~mm}$ diameter holes were cut in the agar using sterile cork borer (plates were in triplicate sets for each plant extract). Plates were inoculated by $0.5 \mathrm{ml}$ of fixed inoculum of Campylobacter jejuni NCTC11168 (600 cell/ml) according to [15]. The inoculum was streaked over the surface of blood agar medium. Plates were dried for $30 \mathrm{~min}$. Holes were filled by $100 \mu \mathrm{l}$ of each concentrated plant extract filtrate. Negative control wells were loaded with the specific plant extract solvent; plates were left in a cooled refrigerator at $4^{\circ} \mathrm{C}$ for one hour for diffusion; then the plates were incubated in the $\mathrm{CO}_{2}$ incubator. At the end of the incubation period, the inhibition zones were measured at three points along the diameter of the plate and the mean was calculated; the inhibition zones in control sets were compared with those of various treatments $[16,17]$.

2.4. Extraction and Solvent-to-Solvent Fractionation. Crude extract was partitioned by extraction with different solvents in order to subfractionate the plant components according to their polarity: hexane, chloroform, ethyl acetate, $n$-butanol, benzene, toluene, and methanol. Every fraction was tested for their antimicrobial activity by well diffusion assay. Controls were prepared for each fraction by drying the same amount of solvents and following the same subfractionation method without plant extract as reported in [18].

2.5. Separation of the Active Crude Plant Extract Using Column Chromatography. A column about $2 \times 25 \mathrm{~cm}$ was used for this purpose. Insert a piece of cotton in the tapering lower end of column. Pack the column with $10 \mathrm{~g}$ silica gel (mix silica gel with chloroform and pour the suspension into column in portions). Allow each part to settle before adding more suspension but without leaving the silica gel to dry. The column was left for $24 \mathrm{~h}$ for complete settling. Only $2 \mathrm{ml}$ of the methanol crude extract was applied cautiously on the top of the column to be fractionated [19].

The column was eluted with gradient solvents using $50 \mathrm{ml}$ volume of the following solvents: hexane, hexane: chloroform $(1: 1 \mathrm{v} / \mathrm{v})$; chloroform:ethyl acetate $(1: 1 \mathrm{v} / \mathrm{v})$; chloroform:ethyl acetate $(1: 2 \mathrm{v} / \mathrm{v})$; ethyl acetate:methanol $(3: 1 \mathrm{v} / \mathrm{v})$, ethyl acetate:methanol $(2: 1 \mathrm{v} / \mathrm{v})$; ethyl acetate: methanol $(1: 1 \mathrm{v} / \mathrm{v})$; and methanol. Fractions were collected each of $3 \mathrm{ml}$. The resultant fractions were analyzed by thinlayer chromatography to check their purity using two solvent systems consisting of toluene:ethyl acetate:formic acid 
$(5: 4: 1 \mathrm{v} / \mathrm{v})$ and chloroform: acetone : isopropanol $(5: 4: 1)$ [20].

Then, $10 \mu \mathrm{l}$ of the resultant fractions was spotted on silica gel plates, which were developed for $2 \mathrm{hrs}$. After development of the plates, the plates were dried at room temperature. The spots were visualized under UV light. Fractions were collected where about 24 fractions were tested for their biological activity against C. jejuni NCTC11168.

\subsection{Determination of the Minimum Inhibitory Concentration} (MIC) for the Purified Compound. Twofold serial dilutions of the active compound were prepared and tested for their biological activity against $C$. jejuni NCTC11168 [21].

2.7. Evaluation of Cytotoxic Effects of the Most Active Fraction against VERO Cell Line. Fresh medium containing different concentrations of the test sample was added after $24 \mathrm{~h}$ of seeding. The microtiter plates were incubated at $37^{\circ} \mathrm{C}$ in a humidified incubator with $5 \% \mathrm{CO}_{2}$ for a period of $24 \mathrm{~h}$. Three wells were used for each concentration of the test sample. Control cells were incubated without test sample and with or without DMSO. After incubation of the cells, viable cells yield was determined by a colorimetric method using a test wavelength of $490 \mathrm{~nm}$ [22].

\subsection{In Vitro Lymphocyte Activation Assay. To} separate lymphocytes, saline solution was added to healthy blood $(1: 1 \mathrm{v} / \mathrm{v})$ then carefully overlaid over Ficoll gradient media which then was centrifuged at $1500 \times g$ for $15 \mathrm{~min}$. Thin-layer medium was carefully withdrawn then cultured on RPMI medium. The most bioactive fraction was purified and dissolved in dimethyl sulfoxide (DMSO) then cultured with separated cells at $37^{\circ} \mathrm{C}$ for $24 \mathrm{~h} \mathrm{[23].}$

\subsection{Transmission Electron Microscopy Preparation. Cells} were centrifuged at $2000 \times g$ for $10 \mathrm{~min}$; then residual cells were fixed in $3 \%$ glutaraldehyde in $0.1 \mathrm{M}$ sodium cacodylate buffer $(\mathrm{pH} 7.0)$ for $2 \mathrm{~h}$ at room temperature, rinsed in the same buffer, and postfixed in $1 \%$ osmium tetroxide for $2 \mathrm{~h}$ at room temperature. The samples were dehydrated in an ethanol series ranging from $10 \%$ to $90 \%$ for $15 \mathrm{~min}$ in each alcohol dilution and finally with absolute ethanol for $30 \mathrm{~min}$. Samples were infiltrated with epoxy resin and acetone through a graded series till finally in pure resin. Ultrathin sections were collected on Formvar-coated copper grids. Sections were then double-stained in uranyl acetate followed by lead citrate. Stained sections were observed with a JEOL JEM 1010 transmission electron microscope at $70 \mathrm{kV}$ at the Regional Center for Mycology and Biotechnology (RCMB), Al-Azhar University [24].

2.10. Determination of the Chemical Properties by Spectroscopic Analysis of the Purified Antibacterial Agent. (A) Mass spectroscopy: mass spectroscopy was carried out using Direct Inlet Unit (DI-50) of SHIMADZU GC/MSQP5050 A. Software: Class 5000. Ionization model: EI.
Ionization voltage: $70 \mathrm{ev}$. Scan speed: $2000 \mathrm{amu} / \mathrm{sec}$. Scan interval: $0.5 \mathrm{sec}$, at the Regional Center for Mycology and Biotechnology, Al-Azhar University

(B) Infrared (IR) spectra: infrared spectrum of the new antimicrobial agent was conducted in potassium bromide using Fourier Transform infrared and Pye Unicam SP300 IR spectrophotometer at the Micro-Analytical Center, Cairo University

(C) The proton nuclear magnetic resonance $\left({ }^{1} \mathrm{H}-\mathrm{NMR}\right)$ : ${ }^{1} \mathrm{H}$-NMR was conducted in deuterated chloroform using Varian Gemini 200 and $300 \mathrm{MHz}$ NMR spectrophotometer at the Micro-Analytical Center, Cairo University.

\section{Results and Discussion}

The inhibitory effect of twenty plant extracts was determined using well diffusion assay and mean diameters of inhibition were recoded as shown in Table 1 . Screening revealed that plants vary in their activity against test microbe. It was found that Rheum officinalis had the most active anti-Campylobacter agent. It was recognized centuries ago that Rheum contained active components like anthraquinones, stilbenes, dianthrones, anthocyanins, flavonoids, galloyl-glucoses, organic acids, phenylbutanones, etc., thus having pharmacological activity [25].

Data revealed that plant extracts had different activities against test microbe where Rosmarinus officinalis, Artemisia, Commiphora myrrha, Cassia angustifolia, and Rheum offcinalis exhibited highest activities, while plant extract Rheum officinalis contained the most effective anti-Campylobacter agent as shown in Table 1.

Extraction with different solvents indicated that methanol was the solvent giving highest growth inhibition action. So, it was used in chromatographic assays as shown in Table 2. In view of the findings of other researchers, various solvents were used for extracting the biosynthesized antimicrobial agents, versus methanol [26], chloroform [27], and ethyl acetate $[18,28]$.

Chromatographic assays indicated that fractions vary in their biological activity against tested microbes where fractions 3-5, fractions 11-15, and fractions 19-23 showed promising antibacterial activities, while fraction 19 was the most active compound against C. jejuni NCTC11168 as shown in Table 3 and Figure 1. In view of the findings of other scientists, column chromatography was packed with silica gel and an eluting solvent composed of various ratios of the solvent system was used for fractionation of the crude extract into active fractions [18]. Separated compounds differ in their activity against test organism. Purification of separated compounds on TLC plates using different solvent systems was utilized, while polar solvents achieved higher antimicrobial activity compared to nonpolar solvents in accordance with [29].

In the present investigation, minimal inhibitory concentration of the antimicrobial agent produced from Rheum officinalis against $C$. jejuni NCTC11168 was $31.25 \mu \mathrm{g} / \mathrm{ml}$ as shown in Table 4 . This result was in complete accordance with [30] for evaluating the antibacterial activity of Thai medicinal plants. 
TABLE 2: Comparative antibacterial activity of different solvents extraction to Rheum officinalis.

\begin{tabular}{lcr}
\hline Solvent & Inhibition zone of crude $(\mathrm{mm})$ & Inhibition zone of solvent $(\mathrm{mm})$ \\
\hline Hexane & $20.2 \pm 0.0$ & 0.0 \\
Chloroform & $12.3 \pm 0.1$ & 0.0 \\
Ethyl acetate & $15.1 \pm 0.14$ & $7.0 \pm 0.0$ \\
$n$-Butanol & $15.0 \pm 0.0$ & 0.0 \\
Benzene & $13.0 \pm 0.0$ & 0.0 \\
Toluene & $18.0 \pm 0.0$ & 0.0 \\
Methanol & $39.1 \pm 0.0$ & 0.0 \\
Fats & $9.0 \pm 0.0$ & 0.0 \\
\hline
\end{tabular}

TABLE 3: Fractionation pattern of antibacterial agents produced by Rheum officinalis, using column chromatography, and their effect against C. jejuni NCTC11168.

\begin{tabular}{lc}
\hline Fraction no. & Inhibited zone $(\mathrm{mm})$ \\
\hline 1 & 0.00 \\
2 & 0.00 \\
3 & $35 \pm 0.00$ \\
4 & $33.3 \pm 0.05$ \\
5 & $36.4 \pm 0.11$ \\
6 & 0.00 \\
7 & 0.00 \\
8 & 0.00 \\
9 & 0.00 \\
10 & 0.00 \\
11 & $32.1 \pm 0.00$ \\
12 & $32.2 \pm 0.00$ \\
13 & $37.7 \pm 0.00$ \\
14 & $38.2 \pm 0.00$ \\
15 & $31.2 \pm 0.00$ \\
16 & 0.00 \\
17 & 0.00 \\
18 & 0.00 \\
19 & $42.3 \pm 0.1$ \\
20 & $39.1 \pm 0.00$ \\
21 & $39.1 \pm 0.00$ \\
22 & $39.3 \pm 0.00$ \\
23 & $39.46 \pm 0.15$ \\
24 & 0.00 \\
\hline
\end{tabular}

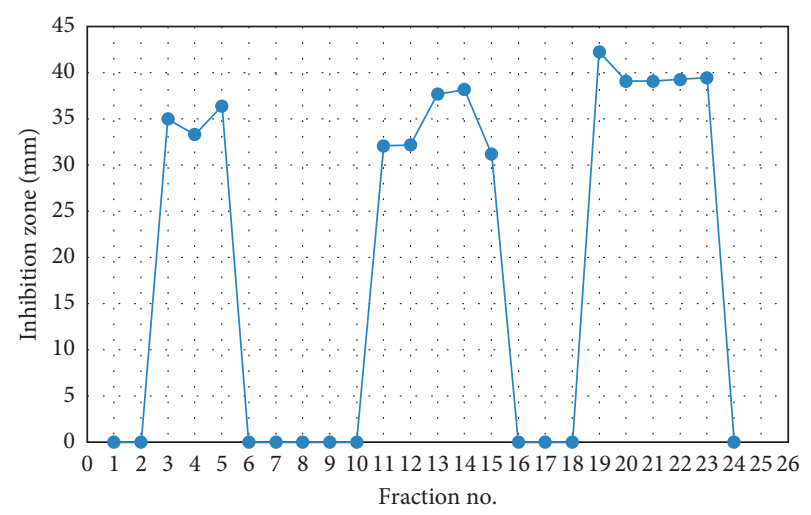

FIGURE 1: Fractionation pattern of antibacterial agents produced by Rheum officinalis, using column chromatography, and their effect against C. jejuni NCTC11168.
TABLE 4: Screening of minimal inhibitory concentration of different concentrations of Rheum officinalis against C. jejuni NCTC11168.

\begin{tabular}{lc}
\hline Concentration $(\mu \mathrm{g} / \mathrm{ml})$ & Inhibited zone $(\mathrm{mm})$ \\
\hline 500 & $42.5 \pm 0.0$ \\
250 & $37.5 \pm 0.0$ \\
125 & $28.6 \pm 0.0$ \\
62.50 & $17.5 \pm 0.0$ \\
31.25 & $11.0 \pm 0.0$ \\
15.62 & 0 \\
7.81 & 0 \\
3.90 & 0 \\
1.95 & 0 \\
0.97 & 0 \\
\hline
\end{tabular}

Cytotoxicity assay indicated that Rheum officinalis has no cytotoxic effects on Vero cells as proposed by [31] where $\mathrm{CC}_{50}$ of Rheum officinalis was $497 \mu \mathrm{g} / \mathrm{ml}$. Rheum officinalis had a very effective antibacterial fraction and induced immune responses by the activation of lymphocytes; these results were in accordance with [32].

The purity of the antibacterial compound was checked by chromatographic separation on silica gel TLC plate that showed one band under short wavelength. Furthermore, the purity of this compound was confirmed by the total ion chromatogram resulting from mass spectroscopic (MS) analysis of this substance that was separated in a single peak for pure compound as shown in Figure 2, and the mass spectrum showed molecular ion peak at $\mathrm{m} / \mathrm{z} 44.86$ (92.39\%), 59.89 (58.96\%), 73.01 (10.02\%), 73.99 (12.23\%), 76.92 (7.36\%), 93.03 (8.03\%), $107.00(4.61 \%), 116.98$ (12.48\%), 144.67 (3.18\%), 146.00 (5.55\%), 172.98 (6.16\%), 205.6 (3.22\%), 231.10 (3.68\%), 261.00 (3.71\%), 274.01 (4.41\%), 278.12 (6.86\%), 290.92 (8.62\%), 292.04 (18.46\%), 293.05 (30.96\%), 307.02 (28.96\%), 320.04 (14.89\%), 324.15 (8.34\%), 345.01 (7.88\%), 346.02 (9.38\%), $361.10(6.51 \%), 362.04$ (9.21\%), 377.11 (7.09\%), 383.08 (7.07\%), 405.03 (4.50\%), 407.98 (6.53\%), 422.14 (8.36\%), 427.09 (13.01\%), 428.12 (12.21\%), and base peak at $\mathrm{m} / \mathrm{z} 426.07$ (100.00\%).

Infrared (IR) spectrum of this compound had absorption bands at 2945 due to the presence of $\mathrm{C}-\mathrm{H}$ aliphatic; band at 1595 due to the presence of $\mathrm{C}=\mathrm{N}$ bonding; band at 1650 due to the presence of $\mathrm{C}=\mathrm{O}$ group of ester; band at 1530 due to the presence of $\mathrm{C}=\mathrm{C}$ bonding; band at 1280 due to the presence of $\mathrm{C}-\mathrm{N}$ bonding; and band at 1080 due to the presence of $\mathrm{C}-\mathrm{H}$ aromatic as shown in Figure 3. 

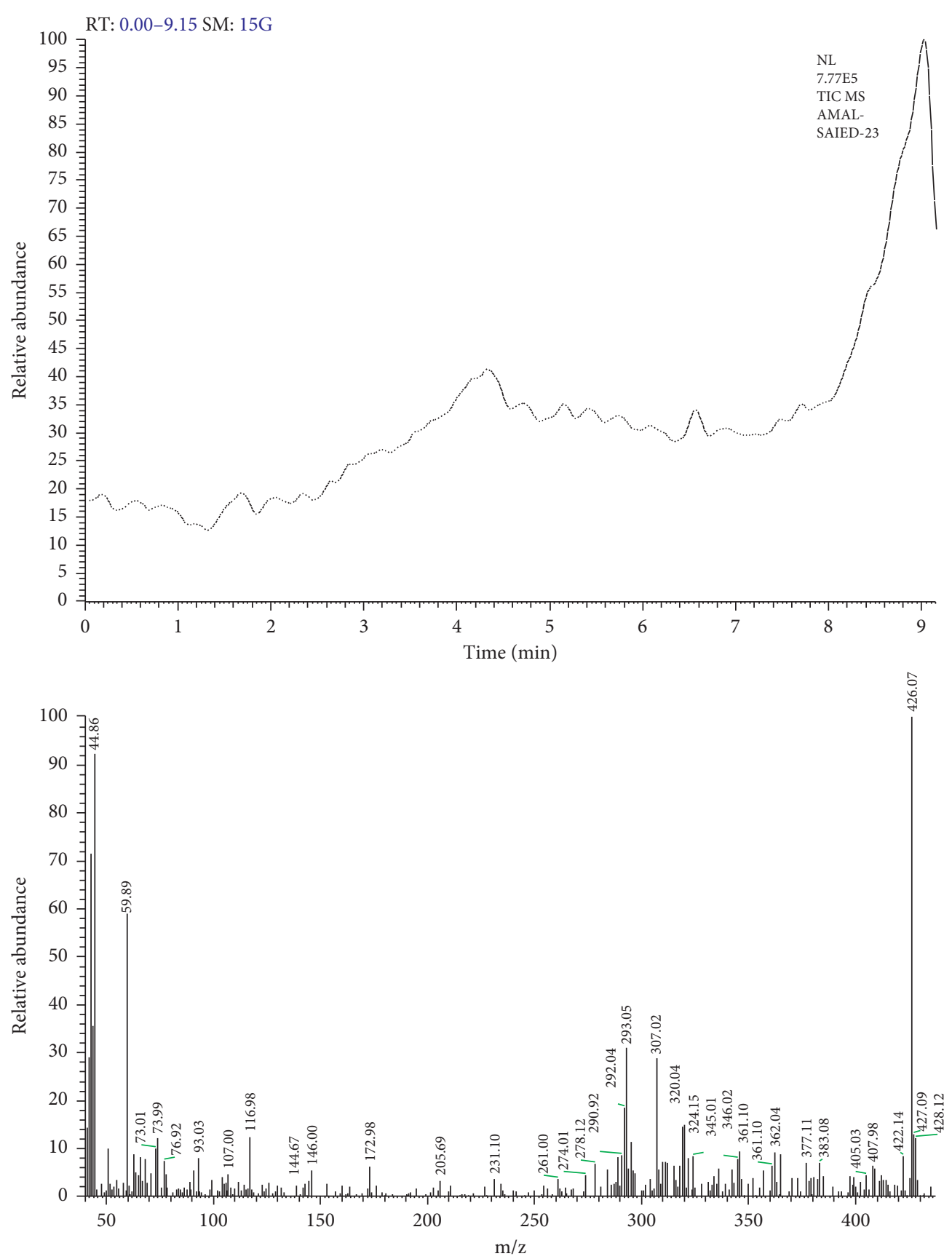

Figure 2: GC-MS of the purified bioactive compound from Rheum officinalis against C. jejuni NCTC11168.

The nuclear magnetic resonance (NMR) spectrum of the compound that dissolved in DMSO-d6 is illustrated in Figure 4; it showed signals at 7.09 and $7.66 \mathrm{ppm}$ indicating the presence of aromatic- $\mathrm{H}$; signals at $0.79 \mathrm{ppm}$ indicate the presence of $\mathrm{CH}_{2}-\mathrm{CH}_{3}$ bonding; signals at $1.15 \mathrm{ppm}$ indicate the presence of $\mathrm{CH}_{3}$ group; and signals at $1.46 \mathrm{ppm}$ indicate the presence of aromatic- $\mathrm{CH}_{2}$.

Consequently, the expected molecular formula for this compound is $\mathrm{C}_{27} \mathrm{H}_{26} \quad \mathrm{~N}_{2} \mathrm{O}_{3}$ and the suggested chemical name is 8-benzyl-2-methyl-3-phenyl-3,7,8,9-tetrahydrooxa3,8diazacyclopenta[A]naphthalene-1-carboxylic acid ethyl ester. The proposed chemical structure is illustrated in Figure 5.
In view of the findings of other investigators, Rheum officinalis is a medicinal herb with clinical practice act as antipyretic, antibacterial, hemostatic, and antineoplastic; this is due to its bioactive components like flavonoids, organic acids, phenyl-butanones, galloyl-glucoses, stilbenes, and anthocyanin [33]. However, [34] reported that Rheum officinalis possessed pharmacological activities due to its phytochemical constituents, thus acting as antioxidants by scavenging free radicals, anticancer effects via inhibiting the cellular proliferation, anti-inflammatory activities through attenuating the activity of TNF- $\alpha$, NF-KB, IL-2, and IL- 6 , and antidiabetic activity via decreasing the activity of glucose-6phosphatase, fructose-1,6-diphosphatase, and aldolase. On the 


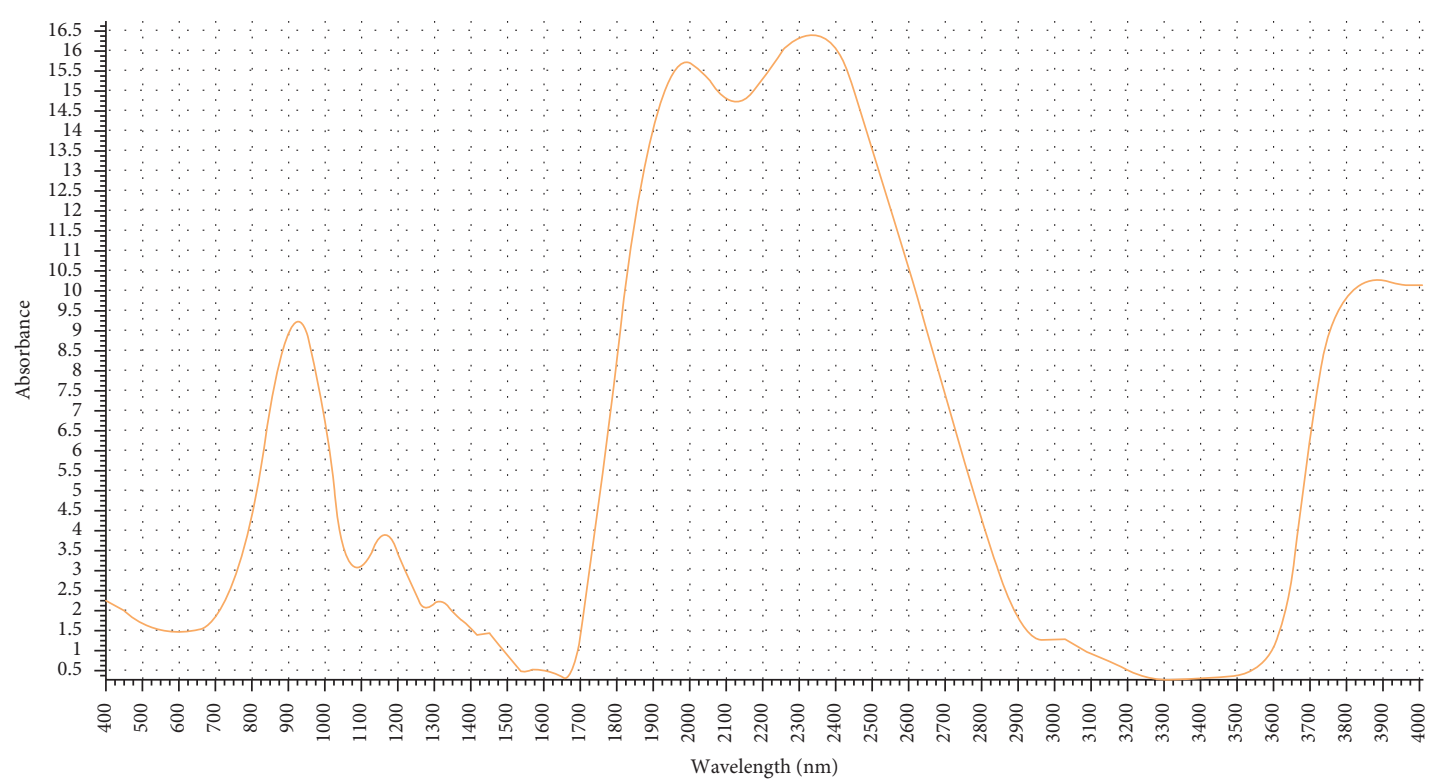

FIGURE 3: IR spectrum of the purified bioactive compound from Rheum officinalis against C. jejuni NCTC11168.

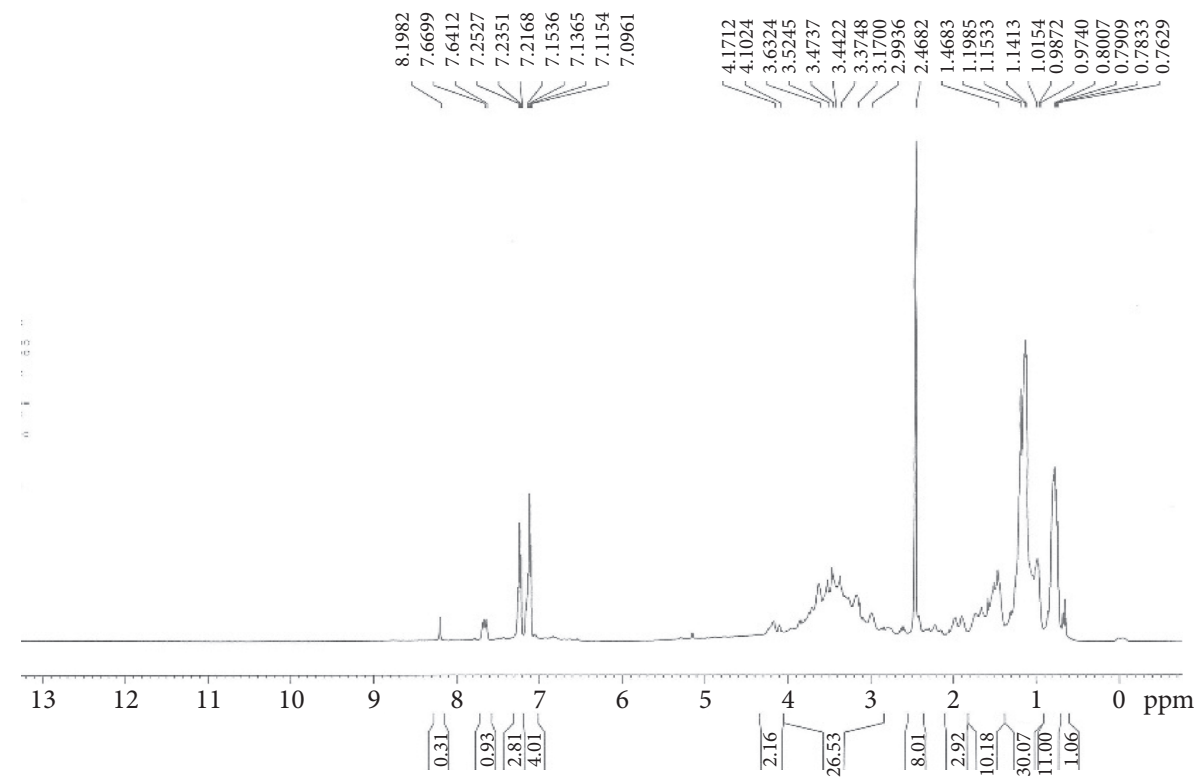

FIGURE 4: NMR spectrum of the purified bioactive compound from Rheum officinalis against C. jejuni NCTC11168.

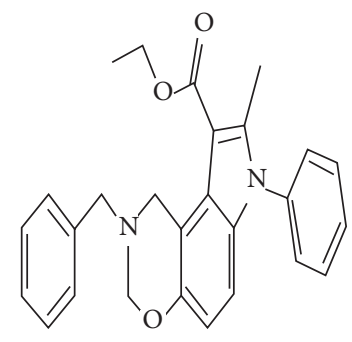

FIGURE 5: Expected formula of the purified compound from Rheum officinalis tested against C. jejuni NCTC11168 (8-benzyl-2-methyl3-phenyl-3,7,8,9-tetrahydro-6-oxa-3,8-diaza-cyclopenta[A]naphthalene-1-carboxylic acid ethyl ester). other hand, raspberry ketone (RK) from Rheum officinalis inhibited melanogenesis by regulation of the posttranscriptional of tyrosinase gene expression [35]. In addition, Rheum officinalis contained tannins and gallic acid which act as antioxidant phenolic components [36].

Moreover, the authors of [37] reported that Rheum spp. contained flavan $\left(3^{\prime}, 5^{\prime}, 5,7\right.$-tetrahydroxyflavanone), pyrones (progallin A), anthrones (10S-3-methyl-1,8,10trihydroxy-10- $\beta$-D-glucopyranosyl- $9(10 \mathrm{H})$-anthracene), and acyl glycosides (4-(4'-hydroxyphenyl)-2-butanone$4^{\prime}$-O- $\beta$-D-glucopyranoside) which are used for treating accumulation and purging, draining damp heat, and cooling blood. Also, [38] indicated that polyphenol 


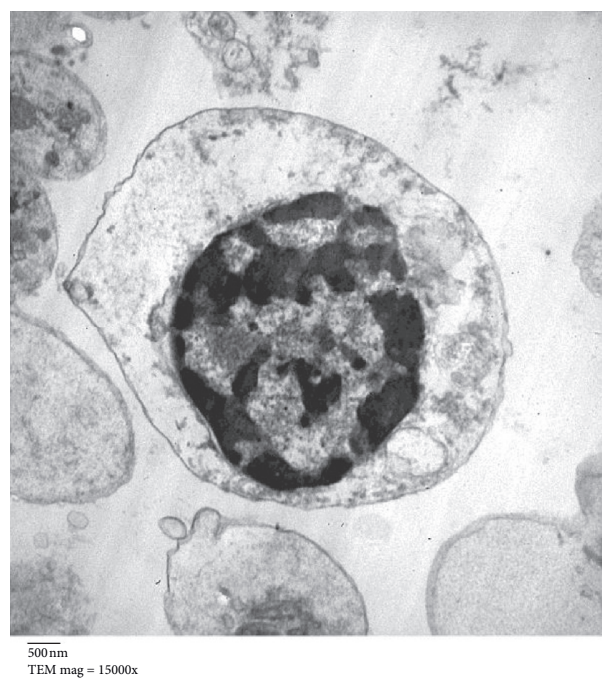

(a)

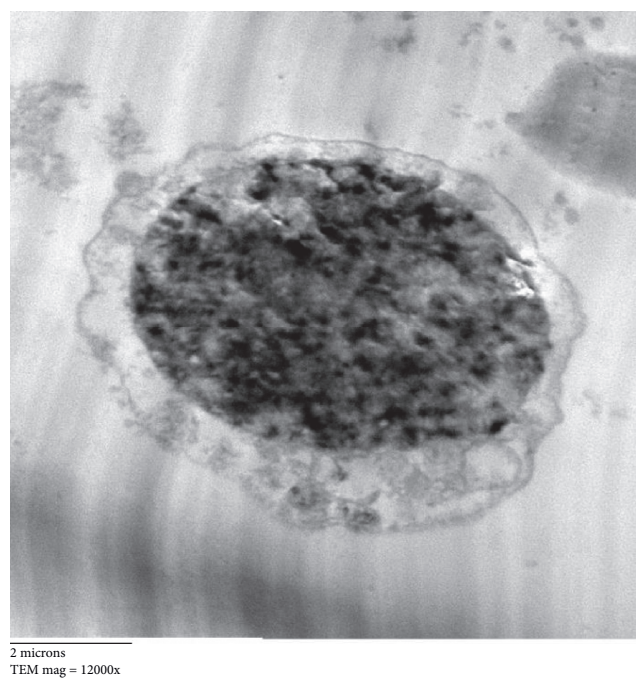

(b)

Figure 6: Effect of the purified compound from Rheum officinalis on isolated human lymphocytes. (a) Control. (b) Treated.

contents from Rheum officinalis were effective against Gram-positive bacteria (Staphylococcus spp.). Furthermore, [39] reported that methyl gallate and its derivatives extracted from Acacia farnesiana showed activity against $C$. jejuni with MIC $50 \mu \mathrm{g} / \mathrm{ml}$. However, our report identified a compound with lower MIC which suggests better antibacterial activity. Moreover, it is recommended to have different bioactive compounds from different sources to be suitable for a wide range of patients.

Additionally, [40] indicated that Rheum spp. has antimicrobial activity against a wide range of pathogens including Candida albicans DSMZ 1386, Enterococcus durans, Enterococcus faecalis ATCC 29212, Escherichia coli ATCC 25922, Klebsiella pneumoniae, Listeria monocytogenes ATCC 7644, Pseudomonas fluorescence P1, Salmonella enteritidis ATCC 13075, Salmonella infantis, Salmonella typhimurium SL 1344, and Staphylococcus epidermidis DSMZ 20044.

In the current study, purified compound activated isolated human lymphocytes as shown in Figure 6. Also, the authors of [41] reported that Rheum officinalis has an immense potential in healthcare as it is regulating gastrointestinal tract, protecting cardiovascular system, and having anticancer, antimicrobial, anti-inflammatory activities, and hepatoprotective activities.

This is the first documentary of the produced compound of 8-benzyl-2-methyl-3-phenyl-3,7,8,9-tetrahydro-6-oxa3,8-diaza-cyclopenta[A]naphthalene-1-carboxylic acid ethyl ester produced by $R$. officinalis in the literature.

\section{Conclusion}

In the current study, chemical composition of bioactive compound derived from of Rheum officinalis against Campylobacter jejuni was identified and elucidated using different solvent systems to isolate the most bioactive compound. Therefore, this approach is successful for the standardization of methods and establishment of results reported for pharmaceutical activities of Rheum officinalis. Further investigations are recommended to test other promising fractions for other future applications.

\section{Data Availability}

All the raw data included in the manuscript are available from the corresponding author upon reasonable request.

\section{Conflicts of Interest}

The authors declare that they have no conflicts of interest regarding the publication of this paper.

\section{References}

[1] S. M. Man, "The clinical importance of emerging Campylobacter species," Nature Reviews Gastroenterology \& Hepatology, vol. 8, no. 12, pp. 669-685, 2011.

[2] E. Bessede, P. Lehours, L. Labadi, S. Bakiri, and F. Megraud, "Comparison of characteristics of patients infected by Campylobacter jejuni, Campylobacter coli, and Campylobacter fetus," Journal of Clinical Microbiology, vol. 52, no. 1, pp. 328-330, 2014.

[3] R. A. Oberhelman and D. N. Taylor, "Campylobacter infections in developing countries," in Campylobacter, I. Nachamkin and M. J. Blaser, Eds., pp. 139-153, American Society for Microbiology, Washington, DC, USA,, 2nd edition, 2000.

[4] N. Asuming-Bediako, A. Parry-Hanson Kunadu, S. Abraham, and I. Habib, "Campylobacter at the human-food interface: the African perspective," Pathogens, vol. 25, no. 2, p. 87, 2019.

[5] M. B. Cook, D. A. Corley, L. J. Murray et al., "Gastroesophageal reflux in relation to adenocarcinomas of the esophagus: a pooled analysis from the Barrett's and Esophageal Adenocarcinoma Consortium (BEACON)," PLoS One, vol. 9, no. 7, Article ID e103508, 2014. 
[6] C. Risch, A. Singh, S. Bhattacharyya et al., "Mucosal delivery of live Lactococcus lactis expressing functionally active JlpA antigen induces potent local immune response and prevent enteric colonization of Campylobacter jejuni in chickens," Vaccine, vol. 38, no. 7, pp. 1630-1642, 2020.

[7] J. A. Khan, R. S. Rathore, H. H. Abulreesh, F. A. Qais, and I. Ahmad, "Prevalence and antibiotic resistance profiles of Campylobacter jejuni isolated from poultry meat and related samples at retail shops in northern India," Foodborne Pathogens and Disease, vol. 15, no. 4, pp. 218-225, 2018.

[8] A. Jaakkonen, R. Kivistö, M. Aarnio, J. Kalekivi, and M. Hakkinen, "Persistent contamination of raw milk by Campylobacter jejuni ST-883," PLoS One, vol. 15, no. 4, Article ID e0231810, 2020.

[9] K. Wieczorek and J. Osek, "A five-year study on prevalence and antimicrobial resistance of Campylobacter from poultry carcasses in Poland," Food Microbiology, vol. 49, pp. 161-165, 2015.

[10] N. M. Sidkey, T. F. Ismail, M. T. Mansour, and N. N. Abed, "Controlling the growth of Campylobacter jejuni, ATCC33291 by antimicrobial agents from microbial origin," in Proceedings of the 8th International Conference of Environment, Development \& Bioinformatics, Al-Azhar-University, Cairo, Egypt, 2012.

[11] S. D. Dwivedi and S. A. Wagay, "Antimicrobial activity of leaf extracts of Jurinea dolomiaea plant against clinical and phytopathogenic bacteria," Chemical and Process Engineering Research, vol. 24, pp. 9-13, 2014.

[12] F. Araniti, A. Lupini, A. Sorgonà et al., "Allelopathic potential ofArtemisia arborescens: isolation, identification and quantification of phytotoxic compounds through fractionationguided bioassays," Natural Product Research, vol. 27, no. 10, pp. 880-887, 2013.

[13] A. Dholvitayakhun, N. Trachoo, U. Sakee, and T. P. Cushnie, "Potential applications for Annona squamosa leaf extract in the treatment and prevention of foodborne bacterial disease," Natural Product Communications, vol. 8, no. 3, pp. 385-388, 2013.

[14] K. Léocadie, M. Renato, B. Elias et al., "Tyrosinase modulation by five Rwandese herbal medicines traditionally used for skin treatment," Journal of Ethnopharmacology, vol. 146, no. 3, pp. 824-834, 2013.

[15] A. Klančnik, S. S. Možina, and Q. Zhang, "Anti-Campylobacter activities and resistance mechanisms of natural phenolic compounds in Campylobacter," PLoS One, vol. 7, no. 12, Article ID e51800, 2012.

[16] M. Anandaraj and N. K. Leela, "Toxic effect of some plant extracts on Phytophthora capsici, the foot rot pathogen of black pepper," Indian Phytopathology, vol. 49, pp. 181-184, 1996.

[17] I. Martin, P. Sawatzky, and G. Liu, "Antimicrobial resistance to Neisseria gonorrhoeae in Canada: 2009-2013," Canada Communicable Disease Report, vol. 41, no. 2, pp. 35-40, 2015.

[18] S. M. Mulvey, M. Elaasser, and H. Elshikh, "Medicinal importance of bioactive compounds produced from marine fungi," African Journal of Biotechnology, vol. 20, no. 2, pp. 1-11, 2015.

[19] C.-H. Chang, Y. Chen, X.-X. Yew et al., "Improvement of erinacine A productivity in Hericium erinaceus mycelia and its neuroprotective bioactivity against the glutamate-insulted apoptosis," LWT-food Science and Technology, vol. 65, pp. 1100-1108, 2016.

[20] F. Liu, S. Han, and Y. Ni, "Isolation and purification of four flavanones from peel of Citrus changshanensis," Journal of
Food Processing and Preservation, vol. 41, no. 6, Article ID e13278, 2017.

[21] J. K. Kovács, P. Felső, L. Makszin et al., "Antimicrobial and virulence-modulating effects of clove essential oil on the foodborne pathogen Campylobacter jejuni," Applied and Environmental Microbiology, vol. 82, no. 20, pp. 6158-6166, 2016.

[22] S. M. Pápai, S. M. Riyadh, E. A. Mahmmoud, and M. M. Elaasser, "Synthesis and anticancer activity of arylazothiazoles and 1,3,4-thiadiazoles using chitosan-graftedpoly(4-vinylpyridine) as a novel copolymer basic catalyst," Chemistry of Heterocyclic Compounds, vol. 51, no. 11-12, pp. 1030-1038, 2015.

[23] N. Abuharfeil, A. Jaran, B. Shabsough, and H. Darmani, "Effects of sodium nitrite on natural killer cells isolated from human peripheral blood," Archives of Toxicology, vol. 75, no. 5, pp. 291-296, 2001.

[24] M. M. Darmani, M. Yosri, and B. H. Amin, "Control of imipenem resistant-Klebsiella pneumoniae pulmonary infection by oral treatment using a combination of mycosynthesized Agnanoparticles and imipenem," Journal of Radiation Research and Applied Sciences, vol. 10, no. 4, pp. 353-360, 2017.

[25] X. S. Fu, F. Chen, X. H. Liu, H. Xu, Y. Z. Zhou, and J. Chin, "Progress in research of chemical constituents and pharmacological actions of Rhubarb," Chinese Journal of New Drugs, vol. 20, no. 16, pp. 1534-1538, 2011.

[26] N. M. Sidkey, E. M. Desoukey, M. S. Ammar, and W. M. Hussein, "Purification and characterization of biologically active substances from Nigella sativa. L. Crude seeds oil," Al-Azhar Journal of Pharmaceutical Science, vol. 26, pp. 40-55, 2000.

[27] K. Burkhardt, H.-P. Fiedler, S. Grabley, R. Thiericke, and A. Zeeck, "New cineromycins and musacins obtained by metabolite pattern analysis of Streptomyces griseoviridis (FH-S 1832). I. Taxonomy, fermentation, isolation and biological activity," The Journal of Antibiotics, vol. 49, no. 5, pp. 432-437, 1996.

[28] N. M. Sidkey, A. A. Aytah, and H. A. Al-Ahmadi, "Antimicrobial activity of Costus plant extract against methicillinresistant Staphylococcus aureus (MRSA, I ${ }_{3}$ ), IJSR, vol. 4, no. 11, pp. 348-359, 2015.

[29] S. Hidayathulla, K. Chandra, and K. R. Chandrashekar, "Phytochemical evaluation and antibacterial activity of pterospermum diversifium blume," International Journal of Pharmacy and Pharmaceutical Sciences, vol. 3, no. 2, p. 166, 2011.

[30] J. L. Ríos and M. C. Recio, "Medicinal plants and antimicrobial activity," Journal of Ethnopharmacology, vol. 100, no. 1-2, pp. 80-84, 2005.

[31] S. C. Kim, S. J. Park, J. R. Lee, J. C. Seo, and C. H. Yang, "Cytoprotective activity of Glycyrrhizae radix extract against arsenite-induced cytotoxicity," Evidence-Based Complementary and Alternative Medicine, vol. 5, Article ID 403632, 7 pages, 2008.

[32] K. Byun and T. Nakayama, "CD4 + T-cell subsets in inflammatory diseases: beyond the Th1/Th2 paradigm," International Immunology, vol. 28, no. 4, pp. 163-171, 2016.

[33] J.-W. Dong, L. Cai, Y.-S. Fang, W.-H. Duan, and Z.-J. Li, "Simultaneous, simple and rapid determination of five bioactive free anthraquinones in radix et rhizoma rhei by quantitative 1H NMR," Journal of the Brazilian Chemical Society, vol. 27, no. 11, pp. 2120-2126, 2016.

[34] M. A. Ding, A. B. Showkat, U. R. Muneeb et al., "Phytochemical analysis and antimicrobial activity of Rheum emodi 
(Rhubarb) rhizomes," The Pharma Innovation Journal, vol. 7, no. 5, pp. 17-20, 2018.

[35] V. L. Hsiang, Y. D. Hsiou, Y. K. Shiou, W. C. Ling, and Y. W. Jiumn, "Evaluation of in vitro and in vivo depigmenting activity of Raspberry ketone from Rheum officinale," International Journal of Molecular Sciences, vol. 12, no. 8, pp. 4819-4835, 2011.

[36] H. S. Cai, T. L. Cui, J. S. Xiao et al., "Evaluation of analgesic and anti-inflammatory activities of Rubia cordifolia L. by spectrum-effect relationships," Journal of Chromatography, vol. 1090, pp. 73-80, 2018.

[37] L. Gao, X. Xu, and J. Yang, "Chemical constituents of the roots of Rheum officinale," Chemistry of Natural Compounds, vol. 49, no. 4, pp. 603-605, 2013.

[38] U. Kosikowska, H. Smolarz, and A. Malm, "Antimicrobial activity and total content of polyphenols of Rheum L. species growing in Poland," Open Life Sciences, vol. 5, no. 6, pp. 814-820, 2010.

[39] E. Hernández-García, A. García, E. Garza-González et al., "Chemical composition of Acacia farnesiana (L) wild fruits and its activity against Mycobacterium tuberculosis and dysentery bacteria," Journal of Ethnopharmacology, vol. 230, no. 230, pp. 74-80, 2019.

[40] K. Canli, Y. Ali, A. Ilgaz, and M. A. Ergin, "In vitro antimicrobial activity screening of Rheum rhabarbarum roots," International Journal of Pharmaceutical Science Invention, vol. 5, no. 2, pp. 01-04, 2016.

[41] Y.-J. Cao, Z.-J. Pu, Y.-P. Tang et al., "Advances in bio-active constituents, pharmacology and clinical applications of rhubarb," Chinese Medicine, vol. 12, no. 1, p. 36, 2017. 